\title{
Disease diagnosis in primary care in Uganda
}

\author{
Martin Kayitale Mbonye ${ }^{1,3^{*}}$, Sarah M Burnett ${ }^{2,3}$, Robert Colebunders ${ }^{3,4}$, Sarah Naikoba ${ }^{1,3}$, \\ Jean-Pierre Van Geertruyden ${ }^{3}$, Marcia R Weaver ${ }^{5}$ and Allan Ronald ${ }^{6}$
}

\begin{abstract}
Background: The overall burden of disease (BOD) especially for infectious diseases is higher in Sub-Saharan Africa than other regions of the world. Existing data collected through the Health Management Information System (HMIS) may not be optimal to measure BOD. The Infectious Diseases Capacity Building Evaluation (IDCAP) cooperated with the Ugandan Ministry of Health to improve the quality of HMIS data. We describe diagnoses with associated clinical assessments and laboratory investigations of outpatients attending primary care in Uganda.

Methods: IDCAP supported HMIS data collection at 36 health center IVs in Uganda for five months (November 2009 to March 2010) prior to implementation of the IDCAP interventions. Descriptive analyses were performed on a cross-sectional dataset of 209,734 outpatient visits during this period.

Results: Over 500 illnesses were diagnosed. Infectious diseases accounted for $76.3 \%$ of these and over $30 \%$ of visits resulted in multiple diagnoses. Malaria (48.3\%), cough/cold (19.4\%), and intestinal worms (6.6\%) were the most frequently diagnosed illnesses. Body weight was recorded for $36.8 \%$ of patients and less than $10 \%$ had other clinical assessments recorded. Malaria smears (64.2\%) and HIV tests (12.2\%) accounted for the majority of 84,638 laboratory tests ordered. Fewer than $30 \%$ of patients for whom a laboratory investigation was available to confirm the clinical impression had the specific test performed.

Conclusions: We observed a broad range of diagnoses, a high percentage of multiple diagnoses including true co-morbidities, and underutilization of laboratory support. This emphasizes the complexity of illnesses to be addressed by primary healthcare workers. An improved HMIS collecting timely, quality data is needed. This would adequately describe the burden of disease and processes of care at primary care level, enable appropriate national guidelines, programs and policies and improve accountability for the quality of care.
\end{abstract}

Keywords: Primary care, Disease diagnosis, Uganda

\section{Background}

Despite recent reductions in both morbidity and mortality, the burden of diseases (BOD) in Sub-Saharan Africa (SSA) remains high when compared with the rest of the world, particularly due to the high burden of infectious diseases [1]. While malaria, tuberculosis and HIV/AIDS remain the leading causes of illness and death in the region, maternal and neonatal complications, diarrheal diseases, pneumonia, and malnutrition are drivers of 'health loss', particularly in children [1]. Concurrently, there has also been an

\footnotetext{
* Correspondence: mbonyemarti@yahoo.com

${ }^{1}$ Infectious Diseases Institute, Makerere University, Mulago Hospital Complex, P.O. BOX 22418, Kampala, Uganda

${ }^{3}$ Department of Epidemiology and Social Medicine, University of Antwerp, Campus Drie Eiken, S.4.10 Universiteitsplein 1, B-2610 Wilrijk, Antwerp, Belgium

Full list of author information is available at the end of the article
}

increase in BOD due to non-communicable diseases (NCD) in adults [1-7].

Little is know about the spectrum of clinical diagnoses encountered at primary care facilities in many SSA countries, including Uganda. Organizations such as the World Bank, the Institute for Health Metrics and Evaluation [1], the World Health Organization [7], and others [2-5] utilize routine health information systems, alongside national representative household surveys and health and demographic surveillance sites, for assessing, estimating and documenting global, regional, country and disease specific BOD [8]. Well collected and analyzed data inform clinical decision support systems $[9,10]$, and enable assessment of disease risk, setting of priorities, evaluations of cost-effectiveness [11] and program efficiency [12], and national planning and policy formulation [13]. 
In Uganda, health information data are collected through the Health Management Information System (HMIS) $[14,15]$ at all levels of the health system. The Medical Form Five (MF5) acts as the case record form and is used to document individual patient data during visits to the outpatient department. Data collected using the MF5 are transcribed into the patient registers, which stay at the health facilities while the original MF5 is retained by the patient [15]. These notes guide patient management during subsequent visits. On a monthly basis, data in the patient registers are aggregated and forwarded to the district and the Ministry of Health $(\mathrm{MoH})$. The Uganda $\mathrm{MoH}$ Resource Centre has the overall responsibility for processing national data collected through the HMIS and use these data to compile annual health sector performance reports [16] statistical abstracts [17] and policy formulation.

Although HMIS data could be a powerful resource for estimating the BOD and developing clinical decision support systems $[18,19]$, its use has been limited by quality limitations, such as underreporting, data loss during aggregation, and erroneous diagnoses [20-25].

The Integrated Infectious Disease Capacity Building Evaluation (IDCAP) sought to estimate the effect of a training program followed by on-site support (OSS) [26] on individual clinical competence [27] and practice, facility-level performance [28,29], and population-based mortality of children under five. To measure facility performance, the IDCAP evaluation team cooperated with the Uganda $\mathrm{MoH}$ to improve the quality of HMIS data through provision of data entry staff and equipment, training and support of supervision visits [30].

We present a review of outpatient visit records from primary care facilities in Uganda from November 2009 to March 2010. While these visits were primarily intended to serve as a baseline for the IDCAP training and quality improvement interventions, they provide a patient-level dataset to examine the potential of using a strengthened HMIS to estimate the BOD.

This article describes outpatient demographic characteristics, common symptoms, investigations, diagnoses and multiple diagnoses recorded in the MF5. It also demonstrates the limitations of clinical diagnosis.

\section{Methods}

\section{Study objectives}

To describe diagnoses, multiple diagnoses or comorbidities, clinical assessments and the extent to which diagnoses are confirmed by laboratory investigations among outpatients presenting at primary care facilities in rural Uganda.

\section{Study design}

This is a cross sectional study that analyzes baseline data collected prior to a large mixed design intervention study described in Naikoba et al. [30]. After these baseline data were collected, two IDCAP interventions were implemented 1) the Integrated Management of Infectious Diseases (IMID) course and 2) on-site support. IMID was for two selected mid-level practitioners (mainly clinical officers and registered nurses) from each of the 36 health facilities conducted at the Infectious Diseases Institute, Makerere University (IDI). It involved a three-week classroom based core course, followed by two one-week booster courses at 12 and 24 weeks after the core course as described in Miceli et al. [26]. On-site support was training and continuous quality improvement which took place at a random sample of 18 of the 36 health facilities. All health workers were invited to participate in the onsite support training as described in Naikoba et al. [30] and Miceli et al. [26].

\section{Study sites and participants}

IDCAP was implemented at 36 health center IVs (HCIV) or comparable health facilities from all administrative regions of Uganda, as depicted in a map in Figure 1, that met the inclusion criteria [30]. The government of Uganda managed thirty sites, five were private not-forprofit sites and one was a private for-profit site with government subsidies. Five sites are small hospitals while 31 are HCIVs. All are the highest healthcare referral point for a health sub-district [31,32]. Each is expected to serve a population of about 100,000 people in the health sub-district, providing basic preventive, curative and referral services with limited inpatient wards. HCIVs also conduct some emergency and surgical and obstetric procedures [17,32]. Staffing norms and level of staffing for a HCIV can be obtained from the $2010 \mathrm{MoH}$ Human Resources for Health Audit Report [33]. Participants included all outpatients at these health facilities.

\section{Data collection, entry and validation}

Data were collected using the MF5 depicted in Figure 2, which was initially modified by the Uganda Malaria Surveillance Project [12] and further revised by IDCAP [28], and includes links between clinical and laboratory data, and 'tick boxes' for history, laboratory investigations, diagnoses and drug prescriptions.

Prior to collecting data, a team comprised of a data management specialist, a medical officer, a clinical officer and a nursing officer introduced the MF5 at each health facility during a one-day training for all health workers. Two key training activities were: 1) an explanation of all variables on the MF5 and the process of collecting outpatient data, and 2) a practical session with the form during routine care. At the end of the day, the health workers met with the trainers to share experiences and offer suggestions to optimize use of the MF5 within the conditions unique to each health facility. Four training teams were created with each team supporting nine health facilities. 


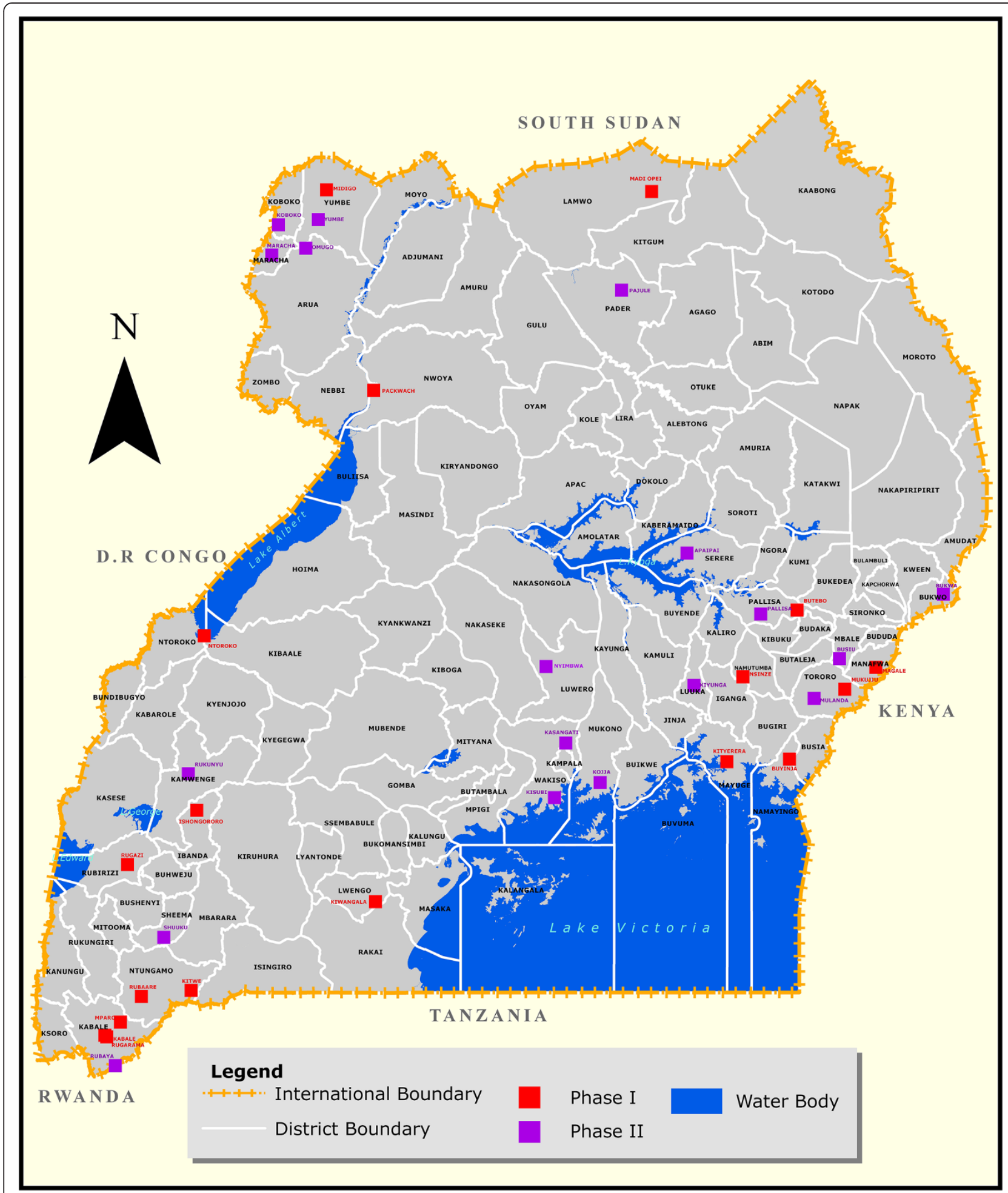

Figure 1 Map of Uganda showing location of IDCAP sites. It is a map of Uganda showing location of all the health facilities that participated in the IDCAP study.

All health facilities consistently started using the MF5 on November 1, 2009. The MF5 collected patient data at various points of care; data on triage and patient demographics at the reception, data on illness history, diagnosis, treatment and referral from the clinician, data on diagnostic investigations and results from laboratory 
Figure 2 The Medical Form 5 used during IDCAP data collection. It is the revised Uganda Ministry of Health Outpatient Medical Form used to capture patient's data during routine care. 
personnel and data on drug availability from a dispenser or pharmacist.

Data were entered into EpiInfo 3.2 ${ }^{\circ}$ (Centers for Disease Control and Prevention, Atlanta GA, US) and transmitted to the central database at the IDI for aggregation, cleaning and analysis. A team of laboratory technicians and clinicians at the IDI supported data cleaning and coding of diagnoses guided by the ICD-10. The process of data collection, entry and validation has been explained previously in more detail [28].

\section{Statistical analysis}

Frequencies and percentages were used for most analyses while cross tabulations were performed to establish relationships between different variables of interest. Although 238,248 patient visits occurred during the data collection period, 28,514 (12\%) MF5s with no record of age or sex variables were excluded, leaving 209,734 records for analysis. All statistical analyses were performed using Stata version 11.0 (StataCorp LP, College Station TX, 2009), and Microsoft Office Excel 2007 (Microsoft Corporation, Redmond WA, 2007).

\section{Ethics Statement}

The original IDCAP protocol was reviewed and approved by the School of Medicine Research and Ethics Committee of Makerere University and the Uganda National Council for Science and Technology. Data collected for the HMIS were part of routine reporting at health facilities and did not require informed consent. The University of Washington Human Subjects Division determined that IDCAP did not meet the regulatory definition of research under 45 CFR 46.102(d). This secondary analysis of anonymous data was also exempt from review by the University of Antwerp ethical review board. Anonymous data are available for public use and instructions for requesting them are on the Accordia Global Health Foundation website (http://www. accordiafoundation.org/IDCAP/data).

\section{Results}

Demographic characteristics, symptoms and exams performed and a summary of diagnosis and treatment decisions for 209,734 patient visits with acute presentations relating to illness or injury are summarized in Table 1 . Of these, 181,529 (97.1\%) were initial presentations for unscheduled appointments. While male and female infants and children under five were equally likely to visit the HCIVs (30,311 vs. 30,381 visits), there were $46.9 \%$ more visits for females aged $14-49$ years (85,138 vs. 45,177 males). Triage status according to the World Health Organization (WHO) Emergency Triage, Assessment and Treatment (ETAT) guidelines [34] were recorded for only 67,997 (32.4\%) visits, of which 6,936 (10.2\%) had 'danger signs' requiring immediate assessment and treatment.
Few patients had their clinical exams recorded: Body weight $(77,141 ; 36.8 \%)$, temperature $(13,820 ; 6.6 \%)$ height $(50 ; 0.024 \%)$ and blood pressure (BP) $(1,769$; $0.85 \%)$. BP recording was often done for older patients (3.9\% among patients 50 or more years) compared to younger patients (1.1\% among patients $14-49$ years and $0.04 \%$ among patients less than five years).

The most frequently reported symptoms were fever, which was recorded in 89,596 (42.7\%) visits, of which only $2,041(2.3 \%)$ were confirmed by a thermometer $\left(>37.5^{\circ} \mathrm{C}\right)$ and cough which was recorded in 54,851 (26.1\%) visits, of which 7,029 (12.8\%) was prolonged for two or more weeks.

Among three assessments for pneumonia recorded in the MF5, breathing rate and abnormal chest sounds were respectively assessed in $101(0.18 \%)$ and 2,043 (3.7\%) of 54,851 patients with a cough, while chest indrawing was assessed in 869 (3.5\%) of 24,960 children less than five years with a cough.

Among the three assessments for tuberculosis, night sweats and weight loss were respectively assessed in $17.5 \%$ and $19.2 \%$ of 7,029 patients with a cough for two or more weeks. Child contact with a TB case was assessed in 474 (11.1\%) of 4,257 children less than 14 years with a cough for two or more weeks.

Overall, 180,492 (86.1\%) visits had at least one diagnosis identified on the MF5, 203,193 (96.9\%) received a drug prescription, 10,743 (5.1\%) were admitted for further care, 3,963 (1.9\%) were referred elsewhere for further care and 297 (0.14\%) were detained for a short time for close monitoring.

\section{Diagnosis}

Overall, over 500 distinct diagnoses (see Additional file 1 ) were made. Infectious diseases $(76.3 \%)$ were the commonly diagnosed illnesses, followed by NCD (10.9\%) and diagnoses that could not be determined according to the ICD-10 (10.6\%) (Table 2). Illnesses that could not be determined according to the ICD-10 included: fatigue, vomiting and nausea, dizziness, and unspecified pain among others.

Similarly, for any specific diagnosis that required a laboratory investigation, fewer than $30 \%$ of patients were confirmed by a diagnostic test (Table 3). For example, only $17.8 \%$ of 101,266 malaria diagnoses were confirmed.

For diagnoses where national statistics were available, our sample of $36 \mathrm{HCIVs}$ had comparable prevalence (Table 3). Malaria (48.3\%), cough/cold (19.4\%), and intestinal worms $(6.6 \%)$ were the commonly diagnosed illnesses.

For each of the top 20 commonly diagnosed illnesses, more females were diagnosed with illnesses than males, with exception of injuries and trauma (Female to Male ratio: 0.9$)$. In some instances, female diagnoses were more 
Table 1 Characteristics of outpatients

\begin{tabular}{|c|c|c|c|}
\hline Parameters & $\begin{array}{l}\text { Male }(\mathrm{N}=82,626) \\
\mathrm{N}(\%)\end{array}$ & $\begin{array}{l}\text { Female }(N=127,108) \\
N(\%)\end{array}$ & $\begin{array}{l}\text { Total }(\mathrm{N}=209,734) \\
\mathrm{N}(\%)\end{array}$ \\
\hline \multicolumn{4}{|l|}{ Age } \\
\hline$<1$ month (Neonates) & $336(0.4)$ & $364(0.3)$ & $700(0.3)$ \\
\hline 1 - 11 months & $8,996(10.9)$ & $9,018(7.1)$ & $18,014(8.6)$ \\
\hline $1-4$ years & $20,979(25.4)$ & $20,999(16.5)$ & $41,978(20.0)$ \\
\hline $5-13$ years & $15,568(18.8)$ & $20,004(15.7)$ & $35,572(17.0)$ \\
\hline $14-49$ years & $29,609(35.8)$ & $65,134(51.2)$ & $94,743(45.2)$ \\
\hline $50+$ & $7,138(8.6)$ & $11,589(9.1)$ & $18,727(8.9)$ \\
\hline \multicolumn{4}{|l|}{ Total attendance } \\
\hline New visits & $70,973(85.9)$ & $110,556(87.0)$ & $181,529(86.6)$ \\
\hline Repeat visits & $2,310(2.8)$ & $3,051(2.4)$ & $5,361(2.6)$ \\
\hline Missing data & $9,343(11.3)$ & $13,501(10.6)$ & $22,844(10.9)$ \\
\hline \multicolumn{4}{|l|}{ Triage status recorded ${ }^{\ddagger}$} \\
\hline Standard & $19,178(23.2)$ & $30,482(24.0)$ & $49,660(23.7)$ \\
\hline Priority & $4,542(5.5)$ & $6,859(5.4)$ & $11,401(5.4)$ \\
\hline Emergency & $2,909(3.5)$ & $4,027(3.2)$ & $6,936(3.3)$ \\
\hline Missing data (no triage data recorded) & $55,997(67.8)$ & $85,740(67.4)$ & $141,737(67.6)$ \\
\hline \multicolumn{4}{|l|}{ Symptoms recorded } \\
\hline Fever & $37,254(45.1)$ & $52,342(41.2)$ & $89,596(42.7)$ \\
\hline No fever & $5,164(6.2)$ & $8,886(7.0)$ & $14,050(6.7)$ \\
\hline Data not recorded on fever & $40,210(48.7)$ & $65,880(51.7)$ & $106,088(50.6)$ \\
\hline Cough & $22,890(27.7)$ & $31,961(25.1)$ & $54,851(26.2)$ \\
\hline Cough $<2$ weeks & $19,792(24.0)$ & $27,589(21.7)$ & $47,381(22.6)$ \\
\hline Cough $>=2$ weeks & $2,908(3.5)$ & $4,121(3.2)$ & $7,029(3.4)$ \\
\hline Cough (not duration not determined) & $190(0.2)$ & $251(0.2)$ & $441(0.2)$ \\
\hline No cough & $8,857(10.7)$ & $14,297(11.2)$ & $23,144(11.0)$ \\
\hline Data not recorded on cough & $50,881(61.6)$ & $80,850(63.6)$ & $131,739(62.8)$ \\
\hline Abnormal chest sounds among patients with a cough & $88(0.3)$ & $104(0.3)$ & $192(0.4)$ \\
\hline No abnormal chest sounds & $764(3.3)$ & $1,087(3.4)$ & $1,851(3.4)$ \\
\hline No data on abnormal chest sounds & $22,038(96.3)$ & $30,770(96.3)$ & $52,808(96.3)$ \\
\hline Breaths per minute among patients with a cough & $51(0.2)$ & $50(0.2)$ & $101(0.2)$ \\
\hline No data on breaths per minute & $22,839(99.8)$ & $31,911(99.8)$ & $54,750(99.8)$ \\
\hline Chest in drawing among children under five with a cough & $67(0.5)$ & $70(0.6)$ & $137(0.5)$ \\
\hline No chest in drawing & $364(2.9)$ & $368(2.9)$ & $732(2.9)$ \\
\hline Missing data on chest in drawing & $12,023(96.5)$ & $12,068(96.5)$ & $24,091(96.5)$ \\
\hline Night sweats among patients with cough $>=2$ weeks & $152(5.2 \%)$ & $147(3.6)$ & $299(4.3)$ \\
\hline No night sweats & $372(12.8)$ & $560(13.6)$ & $932(13.3)$ \\
\hline No data on night sweats & 2,384 (82.0) & $3,414(82.8)$ & $5,798(82.5)$ \\
\hline Weight loss among patients with cough $>=2$ weeks & $138(4.7)$ & $114(2.8)$ & $252(3.6)$ \\
\hline No weight loss & $446(15.3)$ & $651(15.8)$ & $1,097(15.6)$ \\
\hline No data on weight loss & 2,324 (79.9) & $3,356(81.4)$ & $5,680(80.8)$ \\
\hline Child under 14 with a cough $>=2$ weeks in contact with a TB case & $37(0.22)$ & $43(0.23)$ & $80(0.23)$ \\
\hline Child not in contact with a TB case & $2,802(16.6)$ & $3,920(21.1)$ & $6,722(19.0)$ \\
\hline No data on child contact with a TB case & $14,005(83.2)$ & $14,783(78.7)$ & $28,618(81.0)$ \\
\hline
\end{tabular}


Table 1 Characteristics of outpatients (Continued)

\begin{tabular}{llll}
\hline Exams recorded & & & \\
Temperature & $5,688(6.9)$ & $8,132(6.4)$ & $13,820(6.6)$ \\
Weight & $30,980(37.5)$ & $46,161(36.3)$ & $77,141(36.8)$ \\
Blood Pressure & $522(0.63)$ & $1,247(0.98)$ & $1,769(0.84)$ \\
Height & $21(0.03)$ & $29(0.02)$ & $50(0.02)$ \\
No symptom and exam checkboxes filled & $33,915(41.1)$ & $55,009(43.3)$ & $88,924(42.4)$ \\
Diagnosis and treatment decisions & & & $180,492(86.1)$ \\
$\quad$ Diagnosis recorded & $70,721(85.6)$ & $109,771(86.4)$ & $203,193(96.9)$ \\
$\quad$ Treatment prescribed & $79,639(96.4)$ & $123,554(97.2)$ & $3,963(1.9)$ \\
$\quad$ Referred for further care & $1,712(2.1)$ & $2,251(1.8)$ & $170(0.13)$ \\
$\quad$ Detained for monitoring & $127(0.16)$ & $5,657(4.5)$ & $10,743(5.1)$ \\
$\quad$ Admitted & $5,086(6.2)$ & $0.14)$ \\
\hline
\end{tabular}

₹Triage status was established according to the World Health Organization Emergency Triage, Assessment and Treatment (ETAT) guidelines.

than two times higher than that of males (sexually transmitted infections, gastrointestinal (GI) disorders, high BP and arthritis).

Many of the diagnoses were evenly distributed across age groups with some exceptions (see Additional file 2). Malaria (median age $=10$ years), diarrhea (median age $=$ 1 year), pneumonia (median age $=3$ years) and anemia (median age $=2$ years) were often diagnosed among younger patients, while arthritis (median age $=44$ years) and high BP (median age $=55$ years) were often diagnosed among older patients.

Several cases of diseases of epidemic potential were reported with dysentery $(915,0.44 \%)$ the most frequently diagnosed. Acute flaccid paralysis was diagnosed in 77 patients; meningococcal meningitis in 66; measles in 45 and yellow fever in 17. The top five most prevalent neglected tropical diseases included 78 cases of schistosomiasis; 45 of leprosy; 44 of filariasis (general); 31 of onchocerciasis and 19 of guinea worm.

The top 5 NCD appeared among the top 20 commonly diagnosed illnesses with the commonest being: miscellaneous GI disorders 11,519 (5.5\%), injuries/trauma

Table 2 Summary of disease episodes by category of disease diagnosed

\begin{tabular}{ll}
\hline Disease category & $\mathbf{N}(\mathbf{\%}) \mathbf{n}=\mathbf{2 5 4 , 9 8 3}$ \\
\hline Infectious/communicable diseases & $194,492(76.3)$ \\
Non communicable diseases \& injuries & $27,891(10.9)$ \\
Diagnosis not determined according to the ICD-10 & $27,081(10.6)$ \\
Indeterminate/ineligible diagnosis (diagnosis was & $3,348(1.3)$ \\
written on the MF5 but could not be understood) & \\
Diseases of epidemic potential & $1,189(0.5)$ \\
Maternal and perinatal conditions & $760(0.3)$ \\
Neglected tropical diseases & $222(0.1)$ \\
\hline
\end{tabular}

4,618 (2.2\%), anemia 1,515 (0.7\%), high BP 1,437 (0.7\%) and arthritis 1,074 (0.5\%).

\section{Laboratory investigations}

Table 4 shows the distribution of commonly conducted laboratory tests, results, and link between positive/abnormal results and diagnosis for related illnesses.

Overall, 84,638 laboratory tests were ordered during $56,117(28.8 \%)$ visits. Not all tests done had results recorded (range: 50\% for sickle cell tests and $91.4 \%$ for CATT). Of the 48,280 malaria tests with results, 22,806 $(47.2 \%)$ were positive for malaria. Although malaria (48.5\%) topped the disease prevalence list, only $17.8 \%$ was confirmed (Table 3 ). While 10,321 patients were offered an HIV test, the test was not conducted for 20 of them. Of the 10,301 HIV tests conducted, 8,768 (85.1\%) had a result recorded, of which $844(9.6 \%)$ were positive. Two tests (VDRL and RPR) to determine syphilis and other STIs were done of which $16.6 \%$ and $12.2 \%$ respectively were positive. For urinalysis and stool analysis, $43.2 \%$ and $28.8 \%$ of the tests done indicated a positive result, while $79.4 \%$ of 2,608 hemoglobin tests with results indicated anemia.

Usually, patients who test positive for malaria should be assessed for anemia. Additional analysis showed that, among the 22,806 patients with a positive smear result for malaria, only 1,438 (6.3\%) had hemoglobin measured of which $1,188(82.6 \%)$ were anemic.

Generally, apart from malaria (79.1\%), a lot of positive/abnormal test results did not have a record of diagnosis for a related illness.

\section{Multiple diagnoses and comorbidities}

Among the 180,492 (86.1\%) outpatient visits with diagnoses, 63,414 (35.1\%) had multiple diagnoses (Table 3). For example, of the 101,266 malaria diagnoses, 48,954 (48.3\%) had additional diagnoses. Table 5 reports comorbidities 
Table 3 Distribution of commonly diagnosed diseases

\begin{tabular}{|c|c|c|c|c|c|c|c|c|}
\hline \multirow[t]{2}{*}{ No } & \multirow[t]{2}{*}{ Diagnosis } & \multirow{2}{*}{$\begin{array}{l}\text { National } \\
\text { (MoH - HMIS } \\
\text { reported)† }\end{array}$} & \multicolumn{2}{|c|}{$N=209,734$} & \multirow{2}{*}{$\begin{array}{l}\text { Median } \\
\text { age }\end{array}$} & \multirow{2}{*}{$\begin{array}{l}\text { Sex Ratio } \\
\text { F/M }\end{array}$} & \multirow{2}{*}{$\begin{array}{l}\text { Laboratory } \\
\text { confirmed } \\
\mathrm{N}(\%)\end{array}$} & \multirow{2}{*}{$\begin{array}{l}\text { Multiple } \\
\text { diagnoses } \\
\mathrm{N}(\%)\end{array}$} \\
\hline & & & $\mathrm{N}$ & $\%(95 \% \mathrm{Cl})$ & & & & \\
\hline \multicolumn{9}{|c|}{ Top 20 diagnoses } \\
\hline 1 & Malaria & 47.3 & 101,266 & $48.3(48.1,48.5)$ & 10 & 1.47 & $18,051(17.8)$ & $48,954(48.3)$ \\
\hline 2 & Cough or cold & 23.7 & 40,669 & $19.4(19.2,19.6)$ & 9 & 1.48 & N/A & $27,295(67.1)$ \\
\hline 3 & Intestinal worms & 6.4 & 13,892 & $6.6(6.5,6.7)$ & 13 & 1.61 & $198(1.4)$ & $10,525(75.8)$ \\
\hline 4 & Gl disorders* & 2.8 & 11,519 & $5.5(5.4,5.6)$ & 30 & 2.32 & N/A & $6,347(55.1)$ \\
\hline 5 & Pneumonia & 3.2 & 8,335 & $3.9(3.9,4.1)$ & 3 & 1.21 & N/A & $6,003(72.0)$ \\
\hline 6 & Diarrhea & 3.6 & 8,137 & $3.9(3.8,4.0)$ & 1 & 1.15 & N/A & $6,409(78.8)$ \\
\hline 7 & Skin diseases & 3.7 & 8,028 & $3.8(3.7,3.9)$ & 12 & 1.26 & N/A & $3,689(46.0)$ \\
\hline 8 & Urinary Tract Infection & 2.3 & 7,043 & $3.4(3.3,3.4)$ & 27 & 1.99 & $500(7.1)$ & $3,886(55.2)$ \\
\hline 9 & Oral diseases & - & 4,832 & $2.3(2.2,2.4)$ & 21 & 1.48 & N/A & $1,146(23.7)$ \\
\hline 10 & Injuries, Trauma* & - & 4,618 & $2.2(2.1,2.3)$ & 22 & 0.90 & N/A & $1,095(23.7)$ \\
\hline 11 & Eye conditions & 2.4 & 3,782 & $1.8(1.7,1.9)$ & 16 & 1.20 & N/A & $1,736(45.9)$ \\
\hline 12 & Ear Nose \& Throat Conditions & - & 3,762 & $1.8(1.7,1.9)$ & 17 & 1.62 & N/A & $1,787(47.5)$ \\
\hline 13 & Pelvic Inflammatory Disease & - & 3,486 & $1.7(1.6,1.7)$ & 30 & N/A & N/A & $1,790(51.4)$ \\
\hline 14 & Sexually Transmitted Infections & 2.8 & 3,338 & $1.6(1.5,1.7)$ & 28 & 2.19 & $117(3.5)$ & $1,491(44.6)$ \\
\hline 15 & Anemia* & - & 1,515 & $0.72(0.69,0.76)$ & 2 & 1.19 & $408(27.0)$ & $1,307(86.3)$ \\
\hline 16 & Cardiovascular - High Blood Pressure* & - & 1,437 & $0.69(0.65,0.73)$ & 55 & 2.76 & N/A & $748(52.1)$ \\
\hline 17 & Typhoid fever & - & 1,390 & $0.66(0.63,0.70)$ & 25 & 1.52 & $302(21.7)$ & $829(59.6)$ \\
\hline 18 & HIV/AIDS & - & 1,275 & $0.61(0.58,0.64)$ & 32 & 1.82 & $251(19.7)$ & $720(56.5)$ \\
\hline 19 & Asthma* & - & 1,095 & $0.52(0.49,0.55)$ & 36 & 1.58 & N/A & $475(43.4)$ \\
\hline 20 & Arthritis, all cases & - & 1,074 & $0.51(0.48,0.54)$ & 46 & 2.43 & N/A & $453(42.2)$ \\
\hline \multicolumn{9}{|c|}{ Top 5 diseases of epidemic potential } \\
\hline 1 & Dysentery & 0.37 & 915 & $0.44(0.41,0.47)$ & 14 & 1.24 & $41(4.5)$ & $558(61.0)$ \\
\hline 2 & Acute Flaccid paralysis & 0.00 & 77 & $0.04(0.03,0.05)$ & 15 & 2.67 & N/A & $60(77.9)$ \\
\hline 3 & Meningitis (Meningococcal) & 0.00 & 66 & $0.03(0.02,0.04)$ & 13.5 & 0.89 & $0(0)$ & $23(34.9)$ \\
\hline 4 & Measles & 0.00 & 45 & $0.02(0.015,0.028)$ & 2 & 0.8 & N/A & $33(73.3)$ \\
\hline 5 & Yellow Fever & 0.00 & 17 & $0.01(0.004,0.012)$ & 16 & 1.83 & N/A & $9(52.9)$ \\
\hline \multicolumn{9}{|c|}{ Top 5 neglected tropical diseases } \\
\hline 1 & Schistosomiasis & - & 78 & $0.04(0.03,0.04)$ & 18.5 & 1.33 & $4(5.1)$ & $58(74.4)$ \\
\hline 2 & Leprosy & - & 45 & $0.021(0.02,0.03)$ & 40 & 1.00 & $0(0)$ & $32(71.1)$ \\
\hline 3 & Filiarisis & - & 44 & $0.021(0.01,0.03)$ & 40 & 2.39 & $0(0)$ & $27(61.4)$ \\
\hline 4 & Onchocerciasis & - & 31 & $0.015(0.01,0.02)$ & 25 & 2.88 & $1(3.2)$ & $17(54.8)$ \\
\hline 5 & Guinea worms & - & 19 & $0.009(0.001,0.01)$ & 11 & 1.71 & N/A & $13(68.2)$ \\
\hline \multicolumn{9}{|c|}{ Top 5 maternal and perinatal conditions } \\
\hline 1 & Abortion & - & 298 & $0.14(0.13,0.16)$ & 24.0 & N/A & N/A & $89(29.9)$ \\
\hline 2 & Perinatal conditions in newborns & - & 81 & $0.04(0.03,0.05)$ & 0.00 & 0.98 & N/A & $18(22.2)$ \\
\hline 3 & Puerperal sepsis & - & 43 & $0.02(0.01,0.02)$ & 25.0 & N/A & N/A & $16(37.2)$ \\
\hline 4 & Pregnancy & - & 43 & $0.02(0.01,0.02)$ & 22.0 & N/A & $3(7)$ & $13(30.2)$ \\
\hline 5 & Ovarian cyst & _- & 35 & $0.02(0.01,0.02)$ & 30.0 & N/A & $\mathrm{N} / \mathrm{A}$ & $18(51.4)$ \\
\hline
\end{tabular}

*Top 5 Non-Communicable Diseases.

**Percent is the proportion of patients with any given diagnosis who also had at least one other diagnosis.

†National $\mathrm{MOH}$ statistics are not available for all diagnoses.

\#Data only represents maternal and perinatal conditions that presented in the outpatient department; most patients with these conditions present at the specialized maternal and child health clinics including, antenatal, maternity and postnatal clinics. 
Table 4 Laboratory investigations conducted: top 15 laboratory tests

\begin{tabular}{llllll}
\hline Rank & Laboratory test & Total tests & Results received & $\begin{array}{l}\text { Positive or abnormal } \\
\text { test result }\end{array}$ & $\begin{array}{l}\text { Diagnosed with } \\
\text { a related illness } \\
\text { N (\%) }\end{array}$ \\
\hline 1 & Malaria Test (Blood Smear or RDT) & N (\%) & N (\%) & N (\%) & $18,051(79.1)$ \\
2 & HIV Test (Rapid Test or DNA PCR) & $54,344(64.2)$ & $48,280(88.8)$ & $22,806(47.2)$ & $251(29.7)$ \\
3 & Urinalysis & $10,301(12.2)$ & $8,768(85.1)$ & $844(9.6)$ & $702(52.0)$ \\
4 & Stool Analysis & $4,672(5.5)$ & $3,125(66.9)$ & $1,349(43.2)$ & $414(63.9)$ \\
5 & Hemoglobin (Hb) & $3,713(4.4)$ & $2,252(60.7)$ & $648(28.8)$ & $408(19.7)$ \\
6 & VDRL (Venereal Disease Research Lab test) & $3,467(4.1)$ & $2,608(75.2)$ & $2,071(79.4)$ & $31(10.3)$ \\
7 & Widal & $2,361(2.8)$ & $1,812(76.7)$ & $300(16.6)$ & $302(63.0)$ \\
8 & TB AFB Smear & $2,273(2.7)$ & $1,565(68.9)$ & $480(30.7)$ & $60(53.1)$ \\
9 & BAT (Brucella Agglutination Test) & $1,347(1.6)$ & $757(56.2)$ & $113(14.9)$ & $30(50.9)$ \\
10 & Pregnancy Test & $808(1.0)$ & $569(70.4)$ & $59(10.4)$ & $3(2.8)$ \\
11 & Random Blood Sugar & $306(0.4)$ & $258(84.3)$ & $107(41.5)$ & $25(50.0)$ \\
12 & Blood Grouping and/or Blood Cross March & $225(0.3)$ & $188(73.7)$ & N/A & N/A \\
13 & RPR (Rapid Plasma Reagin Test) & $80(0.1)$ & $57(71.3)$ & $7(12.2)$ & $2(28.6)$ \\
14 & CATT (Card agglutination test for trypanasomiasis) & $81(0.1)$ & $74(91.4)$ & $5(6.8)$ & $0(0)$ \\
15 & Sickle cell test & $64(0.1)$ & $32(50.0)$ & $5(15.6)$ & $1(20.0)$ \\
\hline
\end{tabular}

among the 10 most commonly diagnosed illnesses. The bold text across the diagonal of the table presents mono diagnoses. Column and row percentages are presented in the upper and lower parts of the diagonal of the table respectively. For example, in the upper diagonal (column percentages) of the table, 22,217 (55.6\%) of the 40,669 cough or cold cases were also diagnosed with malaria while in the lower diagonal, 22,217 (21.9\%) of the 101,266 malaria cases were also diagnosed with cough or cold. Among the top 10 diagnoses reported in Table 5, there was a disproportionate overlap among malaria, cough/ cold, pneumonia and diarrhea. In 8,335 patients diagnosed with pneumonia and 8,137 with diarrhea, 5,302 (63.6\%) and 4,822 (59.3\%) respectively were also diagnosed with malaria. Similarly, a high proportion of patients with diarrhea were also diagnosed with cough/cold (23.1\%). Of those diagnosed with intestinal worms or urinary tract infections, there was a high percentage also diagnosed with GI problems (6.1\% and 5.6\%, respectively).

\section{Discussion}

This study, which included 209,734 visits across 36 health facilities, presents a panoramic view of primary care provided in Uganda. Infants and children under five appeared to have equal access to care, regardless of gender, in contrast to some societies where males are disproportionately represented in the under-five population receiving care [35]. In the population 14-49 years, women predominated, with ratio of over $2: 1$, possibly reflecting men's reluctance to seek care.
The disease prevalence pattern found in this study matches national patterns where data is available, with malaria (48.3\%), cough or cold (19.4\%), and intestinal worms (6.6\%) being the most prevalent illnesses [17]. The observed malaria prevalence (47.2\%) among those with confirmed malaria was also comparable to the community parasitemia prevalence reported in the 2009 Uganda malaria indicator survey [36]. The patterns of commonly reported illnesses found in this study are also similar to those observed in most SSA countries outside of Uganda [1]. This study also provides the prevalence of less common infections that are rarely reported.

Although 1,189 (0.5\%) infections of epidemic potential were identified during this period, little is known about investigations done to confirm these diagnoses or control measures instituted. Reports from primary healthcare providers are essential for the early recognition and control of reportable infectious diseases that may place populations at high risk of life threatening epidemics [37]. Ebola outbreaks have occurred on four occasions during the past decade in Uganda and early recognition limited the epidemics. Rapid analysis of HMIS data could identify epidemics early to curtail and control these outbreaks [37-39].

At $10.9 \%$ of total diagnoses, NCD and injuries in Uganda are increasingly becoming an important public health concern, as in the rest of SSA countries [1-7]. Stroke (600-2400 DALYs lost per 100,000) and heart disease (300-600 DALYs lost per 100,000) are rapidly increasing causes of death and disability in SSA, with 
Table 5 Multiple diagnoses among each of the top 10 diagnoses

\begin{tabular}{|c|c|c|c|c|c|c|c|c|c|c|c|}
\hline $\begin{array}{l}\text { N (Column \%) } \\
\text { N (Row \%) }\end{array}$ & Malaria & $\begin{array}{l}\text { Cough } \\
\text { or cold }\end{array}$ & $\begin{array}{l}\text { Intestinal } \\
\text { worms }\end{array}$ & $\begin{array}{l}\text { Gastro } \\
\text { Intestinal } \\
\text { Disorders }\end{array}$ & Pneumonia & Diarrhea & $\begin{array}{l}\text { Skin } \\
\text { diseases }\end{array}$ & $\begin{array}{l}\text { Urinary tract } \\
\text { infections }\end{array}$ & $\begin{array}{l}\text { Oral } \\
\text { diseases }\end{array}$ & $\begin{array}{l}\text { Injuries/ } \\
\text { Trauma }\end{array}$ & $\begin{array}{l}\text { Overall } \\
\text { total }\end{array}$ \\
\hline Malaria & $52,312(51.7 \%)$ & $22,217(54.6 \%)$ & $6,903(49.7 \%)$ & $3,200(27.8 \%)$ & $5,302(63.6 \%)$ & 4,822 (59.3\%) & $1,866(23.2 \%)$ & $2,043(29.0 \%)$ & $677(14.0 \%)$ & $426(10.2 \%)$ & 101,266 \\
\hline Cough or cold & 22,217 (21.9\%) & 13,374 (32.9\%) & 2,559 (18.4\%) & 1,180 (10.2\%) & $0(0.0 \%)$ & $1,877(23.1 \%)$ & 794 (9.9\%) & $369(5.2 \%)$ & $286(5.9 \%)$ & $191(4.6 \%)$ & 40,669 \\
\hline Intestinal worms & $6,903(6.8 \%)$ & $2,559(6.3 \%)$ & $3,367(24.2 \%)$ & $845(7.3 \%)$ & 465 (5.6\%) & $657(8.1 \%)$ & $562(7.0 \%)$ & $505(7.2 \%)$ & $71(1.5 \%)$ & $72(1.7 \%)$ & 13,892 \\
\hline $\begin{array}{l}\text { Gastro Intestinal } \\
\text { disorders }\end{array}$ & $3,200(3.2 \%)$ & $1,180(2.9 \%)$ & 845 (6.1\%) & $5,172(44.9 \%)$ & $153(1.8 \%)$ & $191(2.3 \%)$ & 207 (2.6\%) & $394(5.6 \%)$ & $58(1.2 \%)$ & $71(1.7 \%)$ & 11,519 \\
\hline Pneumonia & $5,302(5.2 \%)$ & $0(0.0 \%)$ & 465 (3.3\%) & $153(1.3 \%)$ & $2,332(28.0 \%)$ & $349(4.3 \%)$ & $113(1.4 \%)$ & $82(1.2 \%)$ & $53(1.1 \%)$ & $19(0.5 \%)$ & 8,335 \\
\hline Diarrhea & $4,822(4.8 \%)$ & $1,877(4.6 \%)$ & 657 (4.7\%) & 191 (1.7\%) & 349 (4.2\%) & $1,728(21.2 \%)$ & 134 (1.7\%) & $79(1.1 \%)$ & 92 (1.9\%) & $18(0.4 \%)$ & 8,137 \\
\hline Skin diseases & $2,049(2.0 \%)$ & 794 (2.0\%) & $562(4.0 \%)$ & $207(1.8 \%)$ & $113(1.4 \%)$ & $134(1.6 \%)$ & 4,339 (54.0\%) & $125(1.8 \%)$ & $53(1.1 \%)$ & $85(2.0 \%)$ & 8,028 \\
\hline Urinary tract infections & $2,043(2.0 \%)$ & $369(0.9 \%)$ & 505 (3.6\%) & 394 (3.4\%) & $82(1.0 \%)$ & $79(1.0 \%)$ & $125(1.6 \%)$ & 3,157 (44.8\%) & $28(0.6 \%)$ & $26(0.6 \%)$ & 7,043 \\
\hline Oral diseases & 677 (0.7\%) & $286(0.8 \%)$ & $71(0.5 \%)$ & $58(0.5 \%)$ & $53(0.6 \%)$ & $92(1.1 \%)$ & $53(0.7 \%)$ & $28(0.4 \%)$ & 3,686 (76.3\%) & $5(0.1 \%)$ & 4,832 \\
\hline Injuries/Trauma & $426(0.4 \%)$ & $191(0.5 \%)$ & $72(0.5 \%)$ & $71(0.6 \%)$ & $19(0.2 \%)$ & $18(0.2 \%)$ & $85(1.1 \%)$ & $26(0.4 \%)$ & $5(0.1 \%)$ & $3,073(73.7 \%)$ & 4,168 \\
\hline Overall total & 101,266 & 40,669 & 13,892 & 11,519 & 8,335 & 8,137 & 8,028 & 7,043 & 4,832 & 4,168 & 209,734 \\
\hline
\end{tabular}

The bold figures across the table diagonal show mono diagnoses.

The percentages in the upper section of the table diagonal are column percentages and are calculated by dividing the number of patients ( $N$ ) by the column total.

The percentages in the lower section of the table diagonal are row percentages and are calculated by dividing the number of patients ( $\mathrm{N}$ ) by the row total.

The percentages in the table diagonal (mono diagnoses) are calculated by dividing the number of patients (N) by either row or column total. Column and row totals for these table diagonal are equal. 
much of this tragic outcome possibly due to longstanding, untreated hypertension [2,6,40-42]. While diagnosis and treatment of hypertension are cost-effective and feasible within primary care, care for chronic illnesses in general requires radically different strategies, including an emphasis on patient education to facilitate treatment adherence, retention in care, and periodic tests of care effectiveness. Given that only $2.6 \%$ of the visits were follow-up for ongoing illnesses, and $0.8 \%$ of the patients had their BP recorded, further efforts and strategies will be needed to build capacity to care for chronic diseases and health outcomes generally [43].

The prevalence of multiple diagnoses or comorbidities among patients diagnosed with malaria, respiratory infections and diarrhea was high and comparable to other recent studies from SSA [1]. In our study, 30.2\% of all patients and $38.9 \%$ of patients less than five years had multiple diagnoses, which is higher than findings from a Tanzania study [44] where it was $22.6 \%$ among young outpatients. Overlap in diagnoses was commonest in patients with malaria, cough/cold, pneumonia, diarrhea and intestinal infections. Of those diagnosed with malaria, our study found that $21.9 \%$ were also diagnosed with cough/cold and $5.2 \%$ with pneumonia, compared to respectively $29.5 \%$ and $7.6 \%$ in Tanzania [44]. This rate of malaria and pneumonia co-infection in young children is much lower than the $37 \%$ reported in a study done 10 years ago in Uganda [45]. In western Kenya [46], 28\% of children with respiratory viral infections had malaria, which is much lower than in $61.4 \%$ of children with cough/cold in our study. These data illustrate the difficulties in making a differential diagnosis between malaria, pneumonia and even a gastrointestinal infection in situations when recommended clinical and laboratory assessments are not routinely performed. Few studies have however examined comorbidities or multiple diagnoses among outpatient populations in SSA [21,45,47]

In order to make these diagnoses, it is expected that clinicians will take a patient's history and conduct basic physical assessment. Clinical history was recorded only $57.6 \%$ of the time and limited use of clinical assessment tools was observed. Weight was recorded in only $38.8 \%$ of patients more than two years old, $53.8 \%$ of patients aged one month to two years, and $38.1 \%$ of neonates. Only $2.1 \%$ of adults aged 14 or more years had a BP recorded. Proper clinical assessments are critical to ensuring high quality of care, but are rarely conducted in SSA. In an era where NCD prevalence in SSA is increasing [1-7], failure to screen for BP [48] and body mass index is a missed opportunity in assessing a patients' potential risk.

Despite laboratory confirmations being one of the most important mechanisms for clinicians to provide more accurate diagnoses, laboratory diagnostics were rarely used, with less than $30 \%$ of patients receiving laboratory confirmation for diagnoses requiring an investigation. All sites had trained laboratory technicians and a functional laboratory that could conduct at least six investigations (HIV rapid tests, malaria blood smears, TB sputum smears, urinalysis, stool analysis, and hemoglobin estimation) [30]. When the laboratory investigations were ordered results were recorded only $50.0 \%$ to $91.4 \%$ of the time. These rates of recording differed by laboratory test with malaria test results most often recorded and sickle cells test least often. Laboratory personnel may prioritize tests that are faster to conduct or those that are more common and can easily be done in batches. At the same time, patients may be less inclined to wait for results that take longer to be recorded. As such, tests that are carried out more quickly are more likely be recorded on the MF5 and returned to the clinician for a diagnosis.

Even when results were recorded, clinicians often appeared to lack confidence in the results. Apart from malaria (79.1\%), many patients with a positive test result did not have a record of a diagnosis for a related illness. Further investigations are needed to determine reasons for this difference. It is also clear many diagnoses that required a laboratory confirmation were made without them given that only $28.8 \%$ of visits for whom a laboratory investigation was needed and available to confirm the clinical impression had the specific laboratory test performed. This underuse of laboratory diagnostics may be leading to many missed or incorrect diagnoses $[49,50]$.

Strengthening of laboratory resources has been previously identified as an important priority in improving health services [24]. Increasing the use of laboratory services requires an appreciation of their value, as well as confidence in their reports [51,52]. Between 2006 and 2012, IDI implemented two projects, Joint Uganda Malaria Training Program and IDCAP, in which they trained clinicians, nurses and laboratory personnel in optimal management of malaria and other infectious illnesses. The training also encouraged shared problem solving and appreciation for each other's contribution to managing the patient. Results showed improved skills, efficient use of laboratory resources and reduction in both costly overtreatment and potentially life threatening inappropriate treatment of malaria patients $[28,51,52]$.

Large databases collected by hundreds of busy individuals must be interpreted with caution. Although missing information, potential erroneous diagnoses [21,23,24], ability to classify diseases according to the ICD-10 which was limited by lack of specificity of diagnosis recorded on the MF5, errors in transcription and inadequacies of the MF5 instrument itself can be considered a potential limitation of our study, this large database of outpatient visits provides a unique opportunity to better understand routine care practices, particularly in rural areas. 


\section{Conclusion}

This analysis provides evidence that there is ample room for improvement in primary care, both for the treatment of infectious and, increasing NCD in rural Uganda. A strong national HMIS has the potential to enable timely collection of high quality BOD data that improves disease surveillance, curtails outbreaks and informs development of national guidelines, programs, and policies that are cost-effective, efficient and focused on local conditions. Such information could then be used to ensure accountability in the health sector and leverage improvements in the quality of care.

\section{Additional files}

Additional file 1: Table S1. Distribution of all diagnoses made at primary care health facilities. This file has a list of all the diseases that were diagnosed during the study period.

Additional file 2: Table S2. Distribution of commonly diagnosed diseases also categorized by age groups. This table shows the analysis and distribution of the commonly diagnosed illnesses by category.

\section{Competing interests}

All authors declare no competing interest.

\section{Authors' contributions}

1) Conception and design: MKM, AR, 2) Acquisition of data: none (only did secondary analysis of data routinely collected through the HMIS), 3) Analysis and interpretation of data: MKM, SMB, RC, SN, JPVG, MRW, AR 4) Drafted the manuscript, MKM, 5) Critically revised the manuscript for important intellectual content: MKM, SMB, RC, SN, JPVG, MRW, AR; and 5) Given final approval of the version to be published: MKM, SMB, RC, SN, JPVG, MRW, AR.

\section{Acknowledgements}

We acknowledge all individuals that were involved in the design and implementation of the IDCAP study, the clinicians who coded the MF5 data according to the ICD-10 and the laboratory technologists at IDI who cleaned all the MF5 laboratory data. This manuscript is dedicated to Merle A. Sande, MD (1939-2007) whose vision led to the creation of the Infectious Diseases Institute as an academic center of excellence at Makerere University. Merle devoted his prodigious energy to uniting colleagues from the partner organizations to write the IDCAP proposal, and seeking funds for the state-of-the art interventions and pioneering evaluation.

\section{Funding source}

IDCAP was supported through grant number 94298 to Accordia Global Health Foundation from the Bill \& Melinda Gates Foundation. The content expressed within this article is that of the authors and does not necessarily reflect positions or policies of the Bill \& Melinda Gates Foundation. The funder did not influence study design, data collection, analysis and interpretation, the writing of this manuscript, nor the decision to submit the manuscript for publication.

\section{Author details}

${ }^{1}$ Infectious Diseases Institute, Makerere University, Mulago Hospital Complex, P.O. BOX 22418, Kampala, Uganda. ${ }^{2}$ Accordia Global Health Foundation, Washington, DC, USA. ${ }^{3}$ Department of Epidemiology and Social Medicine, University of Antwerp, Campus Drie Eiken, S.4.10 Universiteitsplein 1, B-2610 Wilrijk, Antwerp, Belgium. ${ }^{4}$ Department of Clinical Sciences, Institute of Tropical Medicine, Antwerp, Belgium. ${ }^{5}$ International Training and Education Center for Health (I-TECH), Department of Global Health, University of Washington, Seattle, USA. ${ }^{6}$ Department of Medicine, University of Manitoba, Winnipeg, Manitoba, Canada.
Received: 24 June 2014 Accepted: 24 September 2014

Published: 8 October 2014

\section{References}

1. HME, World Bank, Human Development Network: The Global Burden of Disease: Generating Evidence, Guiding Policy — Sub-Saharan Africa Regional Edition. Seattle, Washington: 2013. Available: http://www.healthdata.org/ policy-report/global-burden-disease-generating-evidence-guiding-policysub-saharan-africa-regional.

2. Connor MD, Walker R, Modi G, Warlow CP: Burden of stroke in black populations in sub-Saharan Africa. Lancet Neurol 2007, 6:269-278.

3. Baingana FK, Bos ER: Changing Patterns of Disease and Mortality in Sub-Saharan Africa: An Overview. In Disease and Mortality in Sub-Saharan Africa. Edited by Jamison DT, Feachem RG, Makgoba MW, Bos ER, Baingana FK, et al. Washington DC: The International Bank for Reconstruction and Development/The World Bank; 2006.

4. Tomlinson M, Grimsrud AT, Stein DJ, Williams DR, Myer L: The epidemiology of major depression in South Africa: results from the South African stress and health study. S Afr Med J 2009, 99:367-373.

5. Mbanya JC, Motala AA, Sobngwi E, Assah FK, Enoru ST: Diabetes in sub-Saharan Africa. Lancet 2010, 375:2254-2266.

6. Moran AE, Oliver JT, Mirzaie M, Forouzanfar MH, Chilov M, Anderson L, Morrison JL, Khan A, Zhang N, Haynes N, Tran J, Murphy A, Degennaro V, Roth G, Zhao D, Peer N, Pichon-Riviere A, Rubinstein A, Pogosova N, Prabhakaran D, Naghavi M, Ezzati M, Mensah GA: Assessing the global burden of ischemic heart disease: Part 1: methods for a systematic review of the global epidemiology of ischemic heart disease in 1990 and 2010. Glob Heart 2012, 7:315-329.

7. Mathers CD, Fat DM, Boerma J: The Global Burden of Disease: 2004 Update. Geneva: World Health Organization; 2008. Available: http://www.who.int/ healthinfo/global_burden_disease/GBD_report_2004update_full.pdf.

8. Cibulskis RE, Bell D, Christophel EM, Hii J, Delacollette C, Bakyaita N, Aregawi MW: Estimating trends in the burden of malaria at country level. Am J Trop Med Hyg 2007, 77:133-137.

9. Hasan S, Padman R: Analyzing the effect of data quality on the accuracy of clinical decision support systems: a computer simulation approach. AMIA Annu Symp Proc 2006, 2006:324-328.

10. Mutale W, Chintu N, Amoroso C, Awoonor-Williams K, Phillips J, Baynes C, Michel C, Taylor A, Sherr K, Population Health Implementation and Training - Africa Health Initiative Data Collaborative: Improving health information systems for decision making across five sub-Saharan African countries: Implementation strategies from the African Health Initiative. BMC Health Serv Res 2013, 13(Suppl 2):S9.

11. Erhart A, Thang ND, Xa NX, Thieu NQ, Hung LX, Hung NQ, Nam NV, Toi LV, Tung NM, Bien TH, Tuy TQ, Cong LD, Thuan LK, Coosemans M, D'Alessandro $U$ : Accuracy of the health information system on malaria surveillance in Vietnam. Trans R Soc Trop Med Hyg 2007, 101:216-225.

12. Sserwanga A, Harris JC, Kigozi R, Menon M, Bukirwa H, Gasasira A, Kakeeto S, Kizito F, Quinto E, Rubahika D, Nasr S, Filler S, Kamya MR, Dorsey G: Improved malaria case management through the implementation of a health facility-based sentinel site surveillance system in Uganda. PLoS One 2011, 6:e16316

13. Odhiambo-Otieno GW, Odero WW: Evaluation criteria for the district health management information systems: lessons from the Ministry of Health, Kenya. Afr Health Sci 2005, 5:59-64.

14. Gladwin J, Dixon RA, Wilson TD: Implementing a new health management information system in Uganda. Health Policy Plan 2003, 18:214-224.

15. Government of Uganda: The health management information system. Kampala: Health unit procedure manual, Ministry of Health; 2010. Available: http://www.health.go.ug/hmis/public/tools/HF_Revised_HMIS_Manual_ Revised2_updated_.pdf.

16. Government of Uganda: Annual Health Sector Performance Report. Kampala: Ministry of Health; 2010. Available http://www.kampala.cooperazione.esteri. it/utlkampala/download/REPORT\%20BOOK\%202010-2011.pdf.

17. Government of Uganda: Statistical Abstract 2010. Kampala: Ministry of Health; 2010. Availble: http://www.ubos.org/onlinefiles/uploads/ubos/pdf\% 20documents/PNSD/2010MOHStatAbst.pdf. Accessed: 2014 May 30.

18. Wagner MM, Hogan WR: The accuracy of medication data in an outpatient electronic medical record. J Am Med Inform Assoc 1996, 3:234-244. 
19. Berner ES, Kasiraman RK, Yu F, Ray MN, Houston TK: Data quality in the outpatient setting: impact on clinical decision support systems. AMIA Annu Symp Proc 2005, 2005:41-45.

20. Consulting W: Health Information Systems in Developing Countries; A Landscape Analysis. United States of America: Vital Wave Consulting, United States of America; 2009. Available: http://www.minsa.gob.pe/ogei/ conferenciaops/Recursos/43.pdf

21. Gwer S, Newton CR, Berkley JA: Over-diagnosis and co-morbidity of severe malaria in African children: a guide for clinicians. Am J Trop Med Hyg 2007, 77:6-13.

22. Reyburn H, Mbatia R, Drakeley C, Carneiro I, Mwakasungula E, Mwerinde O, Saganda K, Shao J, Kitua A, Olomi R, Greenwood BM, Whitty CJ: Overdiagnosis of malaria in patients with severe febrile illness in Tanzania: a prospective study. BMJ 2004, 329:1212.

23. Wane W, Gayle GH: Education and Health Services in Uganda, Data for Results and Accountability. Service Delivery Indicators. Washington DC: World Bank; 2013.

24. Petti CA, Polage CR, Quinn TC, Ronald AR, Sande MA: Laboratory medicine in Africa: a barrier to effective health care. Clin Infect Dis 2006, 42:377-382

25. Evans T, Stansfield S: Health information in the new millennium: a gathering storm? Bull World Health Organ 2003, 81:856.

26. Miceli A, Sebuyira LM, Crozier I, Cooke M, Naikoba S, Omwangangye AP, Rayko-Farrar L, Ronald A, Tumwebaze M, Willis KS, Weaver MR: Advances in clinical education: a model for infectious disease training for mid-level practitioners in Uganda. Int J Infect Dis 2012, 16:e708-e713.

27. Weaver MR, Crozier I, Eleku S, Makanga G, Mpanga Sebuyira L, Nyakake J, Thompson M, Willis K: Capacity-building and clinical competence in infectious disease in Uganda: a mixed-design study with pre/post and cluster-randomized trial components. PLoS One 2012, 7:e51319.

28. Mbonye MK, Burnett SM, Burua A, Colebunders R, Crozier I, Kinoti SN Ronald A, Naikoba S, Rubashembusya T, Van Geertruyden JP, Willis KS, Weaver MR: Effect of integrated capacity-building interventions on malaria case management by health professionals in Uganda: a mixed design study with pre/post and cluster randomized trial components. PLoS One 2014, 9:e84945.

29. Weaver MR, Burnett SM, Crozier I, Kinoti SN, Kirunda I, Mbonye MK, Naikoba S, Ronald A, Rubashembusya T, Zawedde S, Willis KS: Improving facility performance in infectious disease care in Uganda: a mixed design study with pre/post and cluster randomized trial components. PLOS One 2014, 9:e103017.

30. Naikoba S, Colebunders R, Van Geertruyden JP, Willis KS, Kinoti SN, Kulubya NM, Mbonye MK, Miceli A, Mpanga-Sebuyira L, Ronald A, Scheld M, Weave MR: Design of a cluster randomized trial assessing integrated infectious diseases training and on-site support for midlevel practitioners in Uganda. Int J Care Pathways 2012, 16:152-159.

31. World Health Organization: Health System Profile for Uganda. Geneva: WHO 2005. Available: www.afro.who.int/en/downloads/doc download/2835uganda.html. Accessed: 2013 October 18.

32. Government of Uganda: Health Sector Strategic and Investment Plan 2010/11 - 2014/15. Kampala: Ministry of Health; 2010. Available: http:// aidsalliance.3cdn.net/e9266246309cee49e2_qbm6bt9wn.pdf Accessed: 2013 September 20

33. Government of Uganda: Human Resources for Health Audit Report. Kampala: Ministry of Health; 2010.

34. Gove S, Tamburlini G, Molyneux E, Whitesell P, Campbell H: Development and technical basis of simplified guidelines for emergency triage assessment and treatment in developing countries. WHO Integrated Management of Childhood IIIness (IMCI) Referral Care Project. Arch Dis Child 1999, 81:473-477.

35. Ganatra B, Hirve S: Male bias in health care utilization for under-fives in a rural community in western India. Bull World Health Organ 1994, 72:101-104.

36. UBOS: Uganda Malaria Indicator Survey 2009. Calverton, Maryland, USA: Uganda Bureau of Statistics; Uganda Ministry of Health; USAID; WHO; 2010. Available: http://dhsprogram.com/pubs/pdf/MIS6/MIS6.pdf. Accessed: 2014 May 15

37. Serwadda D, Mugerwa RD, Sewankambo NK, Lwegaba A, Carswell JW, Kirya GB, Bayley AC, Downing RG, Tedder RS, Clayden SA, Weiss RA, Dalgleish AG: Slim disease: a new disease in Uganda and its association with HTLV-III infection. Lancet 1985, 2:849-852.

38. Wamala JF, Malimbo M, Okot CL, Atai-Omoruto AD, Tenywa E, Miller JR, Balinandi S, Shoemaker T, Oyoo C, Omony EO, Kagirita A, Musenero MM,
Makumbi I, Nanyunja M, Lutwama JJ, Downing R, Mbonye AK: Epidemiological and laboratory characterization of a yellow fever outbreak in Northern Uganda, October 2010-January 2011. Int J Infect Dis 2012, 16:e536-e542.

39. World Health Organization: WHO-Multi-Disease Surveillance Centre. Burkina Faso: Ouagadougou; 2003.

40. Jamison DT: Investing in Health. In Disease Control Priorities in Developing Countries. Edited by Jamison DT, Breman JG, Measham AR, Alleyne G, Claeson M, Claeson M, Evans DB, Jha P, Mills A, Musgrove P. Washington DC: The International Bank for Reconstruction and Development/The World Bank Group; 2006

41. Mbewu A, Mbanya JC: Cardiovascular Disease. In Disease and Mortality in Sub-Saharan Africa. Edited by Jamison DT, Feachem RG, Makgoba MW Bos ER, Baingana FK, Hofman KJ, Rogo KO. Washington DC: The International Bank for Reconstruction and Development/The World Bank; 2006.

42. Kim AS, Johnston SC: Global variation in the relative burden of stroke and ischemic heart disease. Circulation 2011, 124:314-323.

43. Horton R, Lo S: Investing in health: why, what, and three reflections. Lancet 2013, 382:1859-1861.

44. D'Acremont V, Kilowoko M, Kyungu E, Philipina S, Sangu W, Kahama-Maro J, Lengeler C, Cherpillod P, Kaiser L, Genton B: Beyond malaria - causes of fever in outpatient Tanzanian children. N Engl J Med 2014, 370:809-817.

45. Kallander K, Nsungwa-Sabiiti J, Peterson S: Symptom overlap for malaria and pneumonia-policy implications for home management strategies. Acta Trop 2004, 90:211-214.

46. Waitumbi JN, Kuypers J, Anyona SB, Koros JN, Polhemus ME, Gerlach J, Steele M, Englund JA, Neuzil KM, Domingo GJ: Outpatient upper respiratory tract viral infections in children with malaria symptoms in Western Kenya. Am J Trop Med Hyg 2010, 83:1010-1013.

47. Mulholland K: Commentary: comorbidity as a factor in child health and child survival in developing countries. Int J Epidemiol 2005, 34:375-377.

48. Mungati M, Manangazira P, Takundwa L, Gombe NT, Rusakaniko S, Tshimanga M: Factors affecting diagnosis and management of hypertension in Mazowe District of Mashonaland Central Province in Zimbabwe: 2012. BMC Cardiovasc Disord 2014, 14:102.

49. Sekandi JN, Neuhauser D, Smyth K, Whalen CC: Active case finding of undetected tuberculosis among chronic coughers in a slum setting in Kampala, Uganda. Int J Tuberc Lung Dis 2009, 13:508-513.

50. Carter JY, Lema OE, Wangai MW, Munafu CG, Rees PH, Nyamongo JA: Laboratory testing improves diagnosis and treatment outcomes in primary health care facilities. Afr J Lab Med 2012, 1(1):6.

51. Namagembe A, Ssekabira U, Weaver MR, Blum N, Burnett S, Dorsey G, Sebuyira LM, Ojaku A, Schneider G, Willis K, Yeka A: Improved clinical and laboratory skills after team-based, malaria case management training of health care professionals in Uganda. Malar J 2012, 11:44.

52. Ssekabira U, Bukirwa H, Hopkins $H$, Namagembe A, Weaver MR, Sebuyira LM, Quick L, Staedke S, Yeka A, Kiggundu M, Schneider G, McAdam K Wabwire-Mangen F, Dorsey G: Improved malaria case management after integrated team-based training of health care workers in Uganda. Am J Trop Med Hyg 2008, 79:826-833.

\section{doi:10.1186/1471-2296-15-165}

Cite this article as: Mbonye et al:: Disease diagnosis in primary care in Uganda. BMC Family Practice 2014 15:165.

\section{Submit your next manuscript to BioMed Central and take full advantage of:}

- Convenient online submission

- Thorough peer review

- No space constraints or color figure charges

- Immediate publication on acceptance

- Inclusion in PubMed, CAS, Scopus and Google Scholar

- Research which is freely available for redistribution 